\title{
DIARIO DE JOSÉ DONOSO: DE LA POSE Y DEL DOBLE
}

\author{
Leonidas Morales \\ Universidad de Chile \\ lmoralest@vtr.net
}

RESUMEN / ABSTRACT

\begin{abstract}
El trabajo crítico de este artículo tiene como referente un corpus textual construido con lo que se conoce del Diario de Donoso (no publicado completo todavía). A partir de ese corpus, y dentro de la riqueza y complejidad de su problemática, el estudio se centra en dos temas: la "pose" y el "doble". La pose conduce a una teoría sobre la verdad narrativa como producto de un artificio. Mientras el doble, y sus raíces en una "fijación" en el narcisismo, permite asistir a una genealogía de personajes de las novelas de Donoso, igualmente desdoblados.
\end{abstract}

Palabras clave: pose, doble, narcisismo, paranoia, diario.

The critical work of this article encompasses a textual corpus built around José Donoso's unpublished Diario. Considering this corpus and the complex issues it displays, the study focuses on two main themes: pretense and the double. Pretense leads us into a theory of narrative truth that ensues as a result of artfulness. In turn, the double and its roots in a fixation with narcissism reveal a genealogy of characters that also remain divided in Donoso's novels.

KEY WORDS: Pretense, double, narcissism, paranoia, diary.

\section{CORPUS}

¿Qué sabemos de los manuscritos del Diario del escritor chileno José Donoso (1924-1996)? Primero, que están repartidos en los archivos de dos bibliotecas de Estados Unidos: la biblioteca de la Universidad de Iowa y la de la Universidad de Princeton, dos universidades bien conocidas por Donoso como escritor o profesor invitado. Ignoramos cuáles fueron las 
cláusulas bajo las cuales se hicieron las entregas de esos manuscritos, que incluyeron un pago por ellos. En 2006, la hija de Donoso, Pilar, mientras se encontraba veraneando en un balneario del litoral central de "buen tono", Cachagua, y cuando preparaba un libro sobre su padre, publicado tres años después con el título de Correr el tupido velo, nos dice: "descansan sobre mis rodillas seis de los sesenta y cuatro tomos de los diarios de mi padre". En la misma oportunidad informa: "su última anotación es de 1994" (Pilar Donoso 17 y 19) ${ }^{1}$. Puesto que hay noticias de la existencia de este Diario ya en la década del 50, cuando escribía Coronación, su extensión cubriría pues un tiempo superior a los cuarenta años. Una fidelidad a la escritura del Diario comparable a la de Luis Oyarzún, que si la de aquél cubre más años que la de éste es porque Donoso también vivió más. Un año antes de cerrar la escritura del Diario, pensando con autocomplacencia, en una mezcla de fetichismo y narcisismo, en cómo quedarían los manuscritos destinados a Princeton, anota: "Sé que estos cuadernos no morirán conmigo (...). Esta página -es maravilloso y terrible pensarlo- me sobrevivirá en los sótanos climatizados, antibomba de hidrógeno, donde se guarda, me complace decirlo, justo al lado de los originales de Lewis Carroll, de Alicia en el país de las maravillas (el verdadero nombre de Carroll era Dodgson)" (Pilar Donoso 33 y s.).

Aun cuando los 64 tomos de los manuscritos originales del Diario de Donoso no han sido aun publicados, tampoco ha habido en torno a su "secreto" (la escritura del diario se despliega desde y en el "secreto") un cierre absoluto. Es decir, de alguna manera, por diversas vías, han llegado a conocimiento del lector institucional algunos fragmentos y páginas completas. Por lo pronto, el mismo Donoso publicó, en el diario madrileño $A B C$, páginas fechadas entre 1979 y 1989 , pero publicadas por el diario mencionado entre agosto de 1986 y enero de 1990. Patricia Rubio, en el curso de una investigación sobre escritos de Donoso en Madrid y Barcelona, "descubrió" esas páginas y las incorporó, como compiladora y editora, a su libro José Donoso. Diarios, ensayos, crónicas. En el libro las páginas del Diario son algo más de 70. La mayoría corresponde a los años de su regreso a Chile en 1981 y a su experiencia del miedo cotidiano ante la represión durante la dictadura militar, y a su condena de la dictadura. Por eso mismo a Patricia Rubio le sorprende

Sobre las intenciones de Pilar Donoso al publicar su libro, véase la entrevista de Álvaro Matus "El infierno sin límites de José Donoso", publicada en el diario La Tercera, sección Cultura, el 5 de diciembre de 2009. 
que Donoso "haya publicado estos Fragmentos en un diario que fue y sigue siendo reaccionario" (Patricia Rubio 15). Tal vez, y en una estrategia muy propia de Donoso, lo haya hecho justamente para "protegerse" de la represión con la cobertura de un diario reaccionario.

Pasajes de las páginas publicadas por el $A B C$ los conocemos también por otra vía: Pilar Donoso los cita en su libro. Estas citas, que son de los manuscritos originales, permiten observar cambios en las páginas del $A B C$. Me referiré más adelante a uno de estos cambios y a su sentido. Por ahora me interesa señalar dos cuestiones de orden general. Una: cuando es el mismo autor quien publica páginas de su Diario, los cambios en determinadas anotaciones originales parecieran responder a que, en su relectura, se revelan incompletas desde el punto de vista de la lógica de una imagen o de una idea. La segunda cuestión tiene que ver con un problema que plantea todo diario publicado por el mismo escritor. Lo propio del diario es el secreto de su escritura y la conversión del autor en su mismo lector. Los diarios íntimos, a diferencia de los diarios de viaje, no se escriben exactamente para ser publicados. Al hacerlo de alguna manera se subvierte una dimensión fundamental del estatuto del diario íntimo como género, no solo la de su secreto, sino también la de la identidad de la escritura original. En efecto, al publicarlos, el autor inevitablemente cae en la tentación de "corregir", de "mejorar" el original. $Y$ en el peor de los casos, puede también abrir espacio a una autocensura.

Después de las páginas publicadas en el $A B C$ hubo una segunda "incursión" en los manuscritos del Diario, ya no del autor, sino de un tercero. El periodista Marcelo Soto tuvo acceso a los manuscritos guardados en la biblioteca de la Universidad de Iowa (cartas y diarios), copió pasajes y con el material reunido publicó, en el diario La Tercera, en el cuerpo de "Reportajes", tres artículos extensos, los días 27 de abril, 4 y 11 de mayo de 2003 (sobre estos artículos, ver bibliografía final). Los manuscritos del Diario guardados en Iowa son de las décadas del 50 y del 60, cuando Donoso escribía su primera novela, Coronación (1957) y trabajaba en El obsceno pájaro de la noche (1970). Soto no transcribe desde luego páginas completas del Diario. Cita breves fragmentos y describe o comenta situaciones, momentos del Diario, y personajes asociados. Aun cuando establece conexiones importantes entre la información de las anotaciones del Diario y la génesis de novelas del autor, sin duda privilegia (porque periodísticamente "vende") el tema de los amores y la homosexualidad de Donoso. Los artículos de Soto dieron lugar a reacciones de escritores y críticos que vieron en ellos, más que un aporte al conocimiento del Diario y a la comprensión, desde él, de la obra 
de Donoso, la intención dominante de aislar y espectacularizar un aspecto de su biografía, como lo es su sexualidad ${ }^{2}$.

Con posterioridad a los artículos de Marcelo Soto, el lector vuelve a tener noticias del Diario de Donoso, esta vez a través de su hija, Pilar. Como dije al comienzo de este ensayo, ella pudo revisar la totalidad de los manuscritos del Diario, los 64 cuadernos (o "tomos"). En su libro Correr el tupido velo, lo cita. Non son las suyas citas dispersas, ocasionales, sino recurrentes, sistemáticas. Tampoco siempre son breves: con frecuencia son de una extensión considerable. Hasta sería posible determinar que la suma de estas citas de los manuscrito del Diario (más las de algunas cartas de Donoso intercambiadas con su mujer, familiares y amigos), deben representar no menos del 30 o el $40 \%$ de todo el libro. Más aún: resulta ser de una evidencia indesmentible que de todos los textos publicados del Diario de Donoso, los citados por su hija constituyen, hasta ahora, el material más extenso y más importante.

Ahora bien, el corpus textual formado por las páginas publicadas en el $A B C$, los fragmentos transcritos por Marcelo Soto y las citas hechas por Pilar Donoso, si bien representa una parte menor de la totalidad del Diario, puede sin embargo considerarse representativo tanto del tipo de escritura del Diario como de la naturaleza de los temas de que éste se ocupa de manera por lo demás recurrente. En otras palabras, se trata de un corpus suficiente como para sostener una lectura crítica fundada y válida por sí misma, pero con pretensiones de validez generalizable a todo el Diario. Es lo que intentaré en las páginas siguientes. Pero no sin antes fijar un cierto marco de constantes de la escritura del Diario, y, dentro de él, los problemas específicos alrededor de los cuales construiré mi lectura.

Aun cuando parezca innecesario, por obvio, es fundamental no obstante para el análisis decir desde ya que estamos aquí frente a un diario de escritor, es decir, el de alguien que escribe desde su condición activa de escritor. En efecto, en sus anotaciones predominan las materias que remiten de modo directo o mediatizado, explícito o implícito, a su obra narrativa. ¿Pero qué clase de Diario de escritor es este de Donoso? Uno, en primer término, donde su escritura, como la escritura de sus novelas, es una compulsión: para Donoso

2 Por ejemplo, el artículo de Julio Ortega "Los papeles de Donoso" publicado en el suplemento Cultura y Nación del diario argentino Clarín el 21 de agosto de 2003, y el de Arturo Fontaine Talavera "Documentos íntimos de José Donoso", publicado en El Mercurio el 17 de mayo de 2003. 
no es posible dejar de escribir porque dejar de escribir es morir: la muerte es "la falta del lenguaje" (Pilar Donoso 418) ${ }^{3}$. Si se estudia la obra narrativa de Donoso desde el punto de vista de su genealogía, pero no solo dentro de la historia de la novela chilena o de la novela en general, sino en particular de esa genealogía que hunde sus raíces en la subjetividad biográfica del autor, la escritura de este Diario es un lugar privilegiado: es en ella donde el cruce y la convergencia del pensamiento lúcido, de las experiencias biográficas y de la imaginación "fabuladora", dan origen a núcleos narrativos básicos, a formas primarias de sentido, que pasarán, como elementos constitutivos, a la estructuración final de las obras narrativas de Donoso, para encontrar allí su sentido último.

Pero el registro cotidiano de los vaivenes del proceso de creación de obras y del modo en que se inscribe en este proceso la memoria biográfica, sobre todo la memoria de la infancia con sus fijaciones, se produce en y desde el interior de una cotidianeidad de múltiples frentes, todos, de una u otra manera, correlacionados. Así, conviven las anotaciones referidas a los procesos creativos, con otras que tienen como objeto el orden de la familia (plagadas de contradicciones: ama y condena a su mujer, a su hija, a su padre), el retorno de sus obsesiones neuróticas y paranoicas, sus lecturas literarias (con sus rechazos y adhesiones), sus amores homosexuales (siempre problematizados, dominados por el prurito de su ocultamiento), las reflexiones que claramente se insertan en el campo de la teoría literaria y, dentro de ella, de una teoría sobre la enunciación y el lenguaje de la verdad.

El de Donoso es un Diario de singularidad extrema. Su lectura, a ratos, nos sumerge en el mundo de una subjetividad profunda, tensionada si no desgarrada, de opuestos que se llaman como si a uno le faltara el otro. Un mundo que de pronto evoca el "subsuelo" de Dostoievski. Un mundo donde se entremezclan las elaboraciones de un pensamiento lúcido, abierto a los problemas de la literatura, del arte, de la sociedad, empezando por el orden de la sociedad chilena (para Donoso, un orden no ajeno al orden de las pesadillas), con el hermetismo de los signos del inconsciente, que, como decía Freud, era necesario "traducirlos" a la conciencia (Sigmund Freud a) 165 y s.), y que en Donoso, asiduo consultor de psicoanalistas, de pronto, no siempre, entran en una zona iluminada de la conciencia. Un mundo, el de este Diario, de extraordinaria complejidad (que es también la complejidad de 
su riqueza), ambiguo sin duda, pero gracias al cual se hacen visibles para el lector los límites de toda empresa humana, unos límites que ponen a la luz y a la sombra en relaciones de implicación recíproca, o, en otras palabras, que las construcciones luminosas de la literatura, productoras de verdad, se alzan desde las profundas grietas y fisuras del sujeto. Por eso decía Donoso: yo no elijo mis temas, los temas me eligen a mí (Pilar Donoso 113)4. O también: los temas surgen de un "vacío". Si consideramos la trayectoria del género del diario íntimo en Chile, el de Donoso representa un caso único y ejemplar desde el punto de vista de una escritura de los límites de la subjetividad.

Dentro del mundo multiforme y laberíntico del Diario de Donoso, hay desde luego líneas temáticas perfectamente discernibles en su desarrollo. Dos de ellas son el objeto específico de este ensayo. Una de ellas puede leerse desde el ángulo de una teoría literaria. La otra en cambio introduce abiertamente el inconsciente. ¿Cuáles son estas líneas temáticas? La primera pone en la escena de la lectura la figura de la pose. La segunda, la figura del doble. Ambas permitirán una lectura no solo de aspectos fundamentales en la temática del Diario, sino que desde ella, y más allá del Diario mismo, será posible también una entrada en la problemática de la obra de Donoso.

\section{LA POSE}

Para la escritura del diario (una excepción absoluta dentro de los géneros modernos), el secreto es la condición de su producción y de su destinación. Es decir, en ella el emisor es a la vez su receptor. O también: el autor se ofrece como lector de sí mismo. Por eso es que siempre ha constituido una suerte de transgresión a este principio la intromisión del lector institucional en el circuito cerrado de la producción y la destinación. No son pocos los que se mantienen fieles a tal principio, y se abstienen por lo tanto de publicar ellos mismos sus páginas. Algunos de estos diarios, muerto el autor, han sido

\footnotetext{
E1 texto de Donoso sobre este punto, escrito en 1972, dice: "Me parece que el creador no elige sus temas, que al contrario, es elegido por ellos. Estoy seguro de que uno es impulsado hacia ciertos temas, $\mathrm{y}$ hacia ciertos tratamientos de estos temas, por ese oscuro amasijo sepultado que se llama el inconsciente. Que por mucho que se concientice ese inconsciente, siempre será el inconsciente lo que en último término me hace elegir tal palabra, tarjar una para colocar otra en su lugar, desechar una anécdota, desplegar ciertos sectores de un personaje y esconder otros".
} 
descubiertos en archivos y publicados años después. El que pasa por ser uno de los primeros diarios dentro de la tradición moderna, el Diario de Samuel Pepys (1663-1703), llevado entre 1660 y 1669, se publicó a cien años de la muerte del autor. Otros diaristas han dejado establecido expresamente que su publicación solo podrá hacerse después de transcurrido un determinado número de años, cuando (pensará tal vez el autor) el presente de la escritura, al convertirse en pasado, desactive la posible incomodidad (para el diarista o para otros) de algunas anotaciones. Es el caso del Diario de Thomas Mann. Pero también hay escritores de diarios que ellos mismos lo publican en parte o en su totalidad. En Europa el ejemplo más evidente es el Diario de André Gide. Ya vimos que José Donoso también lo hizo, aunque fueron pocas páginas. Asimismo, antes de Donoso, lo había hecho en Chile Luis Oyarzún, publicando algunas de las páginas tempranas de su Diario $^{5}$.

Dos preguntas se vuelven necesarias en este contexto. Si un diario, al pasar de su condición de íntimo, en principio sin destinatario como lo sugiere la definición del género ${ }^{6}$, a un diario publicado para ser leído por un lector institucional, ¿sigue siendo un diario con todas las de la ley?, ¿no está deslizándose de alguna manera hacia el territorio de la autobiografía, también una escritura del yo pero destinada a su publicación? En este desplazamiento desde el secreto a la publicidad, ¿nada ocurre que afecta a la escritura? Justamente, es la escritura fundada en el secreto, sin más límites y restricciones que los que ella misma se da, la que aparece puesta en cuestión con la publicidad, en la medida en que introduce una sospecha respecto a su identidad. No me refiero a los diarios publicados después de la muerte del autor, con o sin cláusulas testamentarias, donde el secreto no desaparece ni es transgredido, sino simplemente entregado por otros por su valor histórico, cultural o literario. Lo problemático tiene que ver con los diarios publicados por el mismo autor, como el de Gide. La escritura constituida en el ámbito del secreto, ¿es la misma que el mismo autor entrega a su lectura pública? $\mathrm{Si}$ es así, estaríamos frente a un caso de evidente "exhibicionismo" (algo no difícil de imaginar en el caso de Gide). Si no es la misma escritura, si el autor introdujo cambios pensando en la publicidad, o, más aún, si el autor

5 Son las reunidas en Semblanzas del tiempo. Santiago, Luis Rivano Editor, 1962.

$6 \quad$ Sobre el problema del secreto y del destinatario en el diario íntimo y los diversos grados de apertura del secreto, véase Jean Rousset, "Le journal intime, textesansdestinataire?" En Poétique. Paris, N 56, noviembre 1983, pp. 435-443. 
excluyó pasajes por estimarlos "incómodos" para ser publicados, es decir, si se autocensuró, ¿no hay, por lo menos, una adulteración de la escritura original, y una puesta del género en el límite de su identidad?

La segunda pregunta, que guarda una relación estrecha con la anterior, nos conduce sin más rodeos al tema que es objeto de este apartado. También esta segunda tiene que ver con el secreto como principio de la identidad del diario. Siendo el secreto el lugar de constitución de la escritura del diario, y no estando sometida por lo mismo a ninguna estrategia impuesta por el destinatario, cosa que siempre ocurre, en otros géneros, cuando hay un destinatario externo de por medio, cualquiera sea (incluso en uno tan "privado" como el de la carta), es lógico pensar que el diario íntimo debería reunir condiciones privilegiadas para transformarse en un espacio de escritura regido por el principio de "sinceridad". ¿Pero qué debería entenderse aquí por escritura de la "sinceridad" en el diario? Sin duda, una entregada a sí misma, a la espontaneidad de su forma y sus contenidos, de sus anotaciones y reflexiones, sin interferencias que desde afuera introduzcan recortes, zonas vedadas, o impongan determinadas cautelas de lenguaje. Es posible imaginar que en aquellos diarios publicados por el mismo autor, la cuestión de la sinceridad aparezca, para el lector, por lo menos bajo sospecha de algún "control" e incluso de la manipulación.

Todo lo dicho en el párrafo anterior es inaplicable a Donoso y a su Diario. Simplemente él no cree en una sinceridad definida en los términos en que lo hemos hecho, que son los términos con los cuales regularmente se asocia la sinceridad de la escritura del diario como género. En varios pasajes de su Diario Donoso aborda este problema. Más adelante veremos cómo, a veces, sitúa el problema de la sinceridad, más allá de los límites de la escritura del diario, en una relación esencial con la identidad problemática del sujeto, del ser humano, y, paralelamente, con la identidad del lenguaje en sí mismo, específicamente del lenguaje literario. Por ahora mantengámonos dentro del marco de la sinceridad en cuanto atributo o propiedad de la escritura del diario.

En 1993 escribe: "No tengo fe en mi capacidad de sinceridad pura y directa". La frase contiene, en su segunda parte, una indicación explícita y fundamental para situar correctamente el problema. En efecto, si bien en la primera parte de la frase dice "No tengo fe en mi capacidad de sinceridad", en la segunda parte de la frase le pone límites a esa incapacidad cuando dice a qué "sinceridad" se refiere: se refiere a la sinceridad "pura y directa". Una que no tendría ninguna suerte de mediación, una expresión primaria, no intervenida. La indicación, o precisión, de la segunda parte de la frase 
abre espacio a otra pregunta: ¿habría entonces una clase de sinceridad que no fuera "pura y directa" y que Donoso pudiera suscribir? A continuación de su frase citada, ofrece una primera elaboración conceptual de una respuesta afirmativa. No tiene fe en una sinceridad pura y directa, pero, agrega, "sí, lo sé, tengo fe en mi capacidad de entregar toda mi sinceridad cifrada en el código de mis libros" (Pilar Donoso 34). Esta sinceridad, al contrario de la otra, no es ya pura y directa sino codificada, es decir, construida.

En el mismo párrafo donde figuran las frases antes citadas, junto a la primera elaboración conceptual de esa sinceridad alternativa, la de una sinceridad codificada, encontramos una segunda elaboración que, con respecto a la primera, tiene la ventaja de su plasticidad y de su mayor riqueza conceptual, puesto que ahora se señala en función de qué opera la codificación. Luego de afirmar que sí es capaz de entregar toda su sinceridad, pero una sinceridad construida o codificada, como la de sus libros (y la de su Diario, hay que agregar), desarrolla su segunda elaboración bajo la forma de una pregunta: “¿Pero no existe también otra sinceridad, más sutil tal vez, más aterrada, o por lo menos con otra verdad, en la pose, en la actitud premeditadamente falsa?" (Pilar Donoso 34). La pose, sinónimo habitual de simulación o inautenticidad, es pues para Donoso la estrategia mediante la cual es posible dar forma a una sinceridad que supere la expresión "pura y directa", ciega en último término, anárquica, mediante una sinceridad como construcción (o codificación) de verdad. A partir de aquí celebra con pasión a los fotógrafos del siglo XIX y a sus retratos. Y de nuevo lo hace bajo la forma de una pregunta: “¿Por qué nuestra pasión -y mi gran pasión, muy en particular- por los retratos del siglo pasado? ¿Por qué Nadar y Julia Margaret Cameron y Lewis Carroll y todos los demás, que fuerzan a sus sitters a tomar poses falsas, de donde sin embargo, sale algo que es verdadero, porque es otra forma de fantasía?" (Pilar Donoso 34). Sin duda, la pose (simulación, artificio: construcción) como estrategia para la construcción de verdad rige toda la producción narrativa de Donoso. Incluso ella permite establecer un claro deslinde con otros narradores latinoamericanos anteriores, algunos que cultivaron un realismo de la sinceridad "directa y pura", de una mímesis lineal o más estricta, para optar en cambio por un realismo producido, por uno cuya identidad se resuelve como punto de llegada y no como punto de partida. En otras palabras, por un realismo construido desde el formato de la pose. La novela de Donoso Casa de campo es justamente un relato concebido como puro artificio, en otras palabras, construido desde el formato de la pose. Para introducir los mecanismos del artificio en su relato, Donoso lo hace mediante una parodia 
del relato decimonónico, que jugaba con el lector haciéndole creer que lo que leía era una "realidad" y no una ficción. Tal vez el principio en que se funda el realismo de Donoso pueda verse operando en los demás narradores del "boom", hasta el punto de constituirse en una marca grupal o generacional.

La proyección del principio de la pose sobre el arte narrativo de Donoso, como anticipé, no pone entre paréntesis la escritura del Diario: también ella responde al mismo principio, solo que en el plano de la biografía, de sus tópicos, experiencias y obsesiones. También en el Diario se trata de armar, con los datos aportados por la realidad, una imagen del sujeto biográfico, del diarista, que sea portadora del "código" de su propia lectura (de su verdad). Cuando piensa que los cuadernos de su Diario quedarán en los sótanos de la biblioteca de Princeton, nada menos que junto a los originales de Alicia en el país de las maravillas, reconoce que "sin duda este hecho me hará falsear un poco -espero que sea muy poco- la imagen de mí mismo que pretendo, pero voy a rajarme para que no sea así. Que lo que quede aquí sea la verdad, y así esta carne viva mía que son mis diarios me sobrevivan además de las fantasías de mis libros" (Pilar Donoso: 34). De modo que si bien estos diarios "podrán ser escudriñados por estudiosos, estos señores no encontrarán sólo un monigote relleno de paja, sino que, si bien no un retrato cándido, encontrarán algo parecido a una estudiada fotografía de Nadar". No un monigote relleno de paja: no relleno con una "sinceridad pura y directa". Sí una verdad construida, "algo parecido a una estudiada fotografía de Nadar" (Pilar Donoso 34).

Al concepto de pose Donoso le da, en el Diario, un campo de validez humana universal: el ser humano, en sí mismo, cada uno de nosotros, no es, en cada momento, sino una pose, es decir, una identidad como construcción, por naturaleza transitoria. Solo que aquí, cuando se refiere a la identidad del sujeto, emplea, en vez de pose, la palabra "máscara", que al final terminan compartiendo significado dentro de una cerrada sinonimia. La idea de "rostro", que sería un equivalente de la "sinceridad pura y directa", es igualmente desechada, y ahora con más radicalidad: ni siquiera admite su existencia "pura y directa". En definitiva, no hay rostro: su existencia pertenece al orden de la mitología de las identidades, al igual que la idea de "origen" en la historia del sujeto. Si no hay rostro, ¿qué hay? Simplemente "máscara". Máscaras que se suceden una tras otra, una a partir de la otra, una desde la otra, donde la máscara nueva hace visible las anteriores como etapas suyas, como vías de tránsito suyo. Las palabras de Donoso sobre la identidad y la máscara son las siguientes: "Lo que hay detrás del rostro de la máscara nunca 
es un rostro. Las máscaras son tú, y la máscara que hay detrás de la máscara también eres tú y así sucesivamente y con todas las otras". Y evocando en el lector de nuevo la idea de sinceridad "pura y directa", dice ahora: "Yo no sé qué es eso de la autenticidad". Y agrega: "Lo que sí creo es que la vida humana consiste en un refinado y complejísimo sistema de enmascaramientos y simulaciones" (Pilar Donoso 34).

\section{EL DOBLE}

El doble, es decir, el otro como yo o yo como el otro, es un tema de vieja tradición: atraviesa las culturas arcaicas y vuelve a emerger en la modernidad. La imagen que nos devuelve el espejo es la forma más elemental del doble, de la duplicación del yo. O también: nuestra sombra al caminar o proyectada por el cuerpo sobre una superficie vertical. El problema del doble, visto desde nuestro presente, tiene implicaciones múltiples: culturales, religiosas, psicológicas. En el siglo XX, quien lo ha tratado de manera sistemática desde el psicoanálisis ha sido Otto Rank, en su libro El doble (ver bibliografía). En una mirada antropológica, y a la luz de la historia de las culturas arcaicas, Rank aísla los dos elementos que para él forman el tejido fundamental de la problemática del doble: el narcisismo y el miedo a la muerte. El amor a sí mismo, el deseo de perpetuación, el no querer ser destruido por la muerte, actúan como condicionantes de la imaginación del doble del yo. Este sería pues el origen mismo de la idea de alma: mientras el yo muere y se destruye, sumergido en la materia orgánica, su doble, el alma, permanece inmortal.

Pero el análisis de Rank se vuelve de particular interés cuando se detiene en el narcisismo y la muerte como categorías psicoanalíticas y las aplica a la literatura moderna del siglo XIX y a la imagen del doble en algunos escritores del período, sobre todo Hoffman, Wilde y Dostoievski. Para la comprensión de la lectura que Rank practica de estos autores, y la que del Diario de Donoso haremos nosotros mismos, importa aquí replantear dos principios del psicoanálisis que resultan fundamentales para dar cuenta del sentido de la figura del doble. En primer lugar dejar establecido que, para el psicoanálisis, el narcisismo es solo una etapa dentro del desarrollo del yo, o del sujeto. Pero cuando esta etapa, por múltiples razones, no es superada en el desarrollo general, puede producirse una "fijación en el narcisismo". Ahora bien, en el análisis de Rank, está fijación está en la raíz, haciéndola posible, de la paranoia, de las conductas y pensamientos paranoicos. Justamente, la 
figura del doble es un producto paranoico, de estados paranoicos. Las citas y comentarios hechos por Rank de Hoffman, Wilde y Dostoievski documentan este principio. Sobre todo los referidos a El retrato de Dorian Gray de Wilde. La evidente fijación en el narcisismo del personaje de esta novela, Dorian, se objetiva en la relación de identificación con el retrato que le ha hecho un pintor amigo. Ese retrato, su doble, recoge el momento de su plena juventud y de su belleza. Un momento que él quisiera eternizar. El temor a dejar de ser esa figura joven y hermosa de su doble, en otras palabras, el temor a la desfiguración y al deterioro, en definitiva el temor a la muerte, lo lleva a afirmar: "Cuando descubra que envejezco, me mataré". Temor a envejecer: temor a la muerte. En el Diario de Donoso se repiten los pensamientos obsesivos en torno al envejecer, a la muerte, o a la enfermedad, aun cuando no se den en el marco de una referencia inmediata a un doble, pero sí dentro de un contexto implícito de narcisismo ${ }^{7}$.

El segundo principio indispensable para la inteligencia del doble tiene que ver con la forma en que el paranoico "regresa a su narcisismo primitivo": regresa, dice Rank, bajo la forma de una "homosexualidad sublimada, contra cuyo estallido indisimulado se defienden con el mecanismo característico de la proyección". El yo se "proyecta" a sí mismo en su doble. Los modos de la proyección y las relaciones específicas entre el yo y su doble (de amor y odio, de temor y atracción, por ejemplo) son variadísimos. En Wilde, el doble narcisista de Dorian es su retrato, una imagen de sí mismo que permanece inmutable en su juventud como objeto del deseo, mientras el yo no puede dejar de sufrir las huellas y las ruinas del tiempo. Rank, en su lectura de la novela de Wilde, observa en el personaje un rasgo perfectamente generalizable a otros casos, entre ellos obviamente el de Donoso. Dice: "Unido a esta actitud narcisista está su imponente egoísmo, su incapacidad para el amor y su vida sexual anormal. Las amistades íntimas con hombres jóvenes, que Hallward le reprocha, son intentos de realizar el enamoramiento erótico con su propia imagen juvenil" (Otto Rank 115).

No caben dudas: el Diario de Donoso pone a su lector frente a la escritura y a la imagen de un paranoico. El mismo lo reconoce y lo advierte en sus

En la historia del género en Chile, el Diario de Alone presenta en su autor una caso de narcisismo extremo, de culto a la juventud, al cuerpo joven, y, paralelamente, de terror a envejecer, a morir. Véase mi ensayo "Alone: Diario de un lector". En Anales de Literatura Chilena $\mathrm{N}^{\mathrm{o}} 20$, diciembre de 2013, pp. 47-65. 
anotaciones sobre tal o cual incidente cotidiano. No son pocas las ocasiones en que informa de sus visitas reiteradas al psiquiatra. Sus relaciones con su hija y con su mujer (contradictorias, inestables, arbitrarias a veces) responden a modelos de comportamiento paranoico. De la misma manera, las páginas del Diario no se restan al registro frecuente de actitudes y pensamientos narcisistas, de sentimientos y actos homosexuales, ni tampoco, como señalaba Rank, al reconocimiento de una incapacidad de amar propiamente a la mujer, empezando por la suya. Pero de este trasfondo biográfico dominado por la paranoia, el foco de nuestro interés crítico se centra en la figura del doble, presente en el Diario de Donoso (aunque también en sus creaciones novelescas).

Las formas bajo las cuales se configura este desdoblamiento del yo en el Diario no son las mismas en cada caso. Me gustaría empezar por una de tono aparentemente más bien liviano, con aire de jardín de la belle époque. En una anotación de 1980, mientras esperan en Madrid el regreso definitivo a Chile, describe una escena que contempla desde su ventana: "Desde la ventana de mi estudio veo, en la tarde tórrida, a la princesa alemana (hija del Rey de Alemania, según chismes de portería), con encrespadores y gritándoles a sus hijitos que jueguen con conejos de felpa. Está leyendo un libro. Desde esta distancia y con el temblor de las hojas de los árboles inmensos, parece ser un libro de mi editorial. ¿Quizás un libro mío? Ella consume, yo produzco. Tengo que terminar este libro mío sobre ella antes que ella termine de leer mi libro. Gestos íntimos porque no sabe que alguien durante todo el día la mira y la ve y queda la crónica. La criada le lleva el té en una bandeja que deja sobre el pasto" (Pilar Donoso 245).

La página donde se encuentra la cita anterior del Diario (fechada en Madrid el 16 de abril de 1980), Donoso la publicará posteriormente en el diario $A B C$. Pero en esta publicación el pasaje antes citado aparece reescrito con algunas variantes reveladoras en el contexto de nuestro análisis. Transcribo el fragmento involucrado: "Tengo que terminar este libro mío sobre ella antes que ella termine de leer mi libro. Si Gloria supiera mi no-relación con esta chica bella y joven, tal vez se moriría. O no. Gestos íntimos porque no sabe que alguien durante todo el día la mira y la ve y queda la crónica. La criada le lleva el té en una bandeja que deja sobre el pasto. Isabel, unánime, me trae el té a mí: tomamos el té juntos" (Patricia Rubio 489).

Dos detalles significativos se agregan en la reescritura. El primero se refiere a una variación en el final de la cita del manuscrito del Diario, que terminaba con esta frase: "La criada le lleva el té en una bandeja que deja sobre el pasto". La página publicada en el $A B C$ agrega, como puede verse, 
otra frase: "Isabel, unánime, me trae el té a mí: tomamos el té juntos". Isabel, "unánime", extiende la unanimidad a ambos personajes: los hace uno. Más que de un simple paralelismo, la escena reescrita habla de un complejo juego de identidades que se desdoblan en planos que terminan confundiéndose. La mujer que el diarista observa, en el plano real, mientras ella lee en el jardín un libro, entra, en el plano de la ficción, como uno de los personajes de la novela El jardín de al lado. El lector del Diario asiste, en verdad, a un proceso de desdoblamientos, especular, que atraviesa y funde, o confunde, la identidad del libro, del lector y del autor. La joven lee un libro, precisamente el libro que el diarista está escribiendo sobre ella, es decir, El jardín de al lado: ¿se lee entonces a sí misma, se mira en el espejo de su propia ficción, cruzando y borrando la frontera que separa lo real de lo ficticio? Más aún, ella lee el libro que su autor aún no ha terminado pero que se apresura para terminarlo "antes" de que ella termine de leerlo: ¿el autor es pues alguien que va a la zaga de su lector, que se le adelanta con la clave soberana de su lectura, haciendo de él un rezagado? Y otra conjetura: puesto que estamos leyendo un diario íntimo, un género donde el autor es su lector, y al revés, la joven que lee y el autor de lo que lee: ¿no podrían ser el mismo, el uno desdoblado en él y ella, y por lo tanto poder decir: "tomamos el té juntos", o mejor: tomamos juntos el mismo té?

El segundo detalle significativo pareciera confirmar la reflexión inspirada por el primero. Se trata de la irrupción de "Gloria", mencionada en la mitad del párrafo reescrito sin que el autor se moleste en decirnos quién es. Ahora bien, Gloria es también un personaje de El jardín de al lado, pero con un estatus muy distinto. Es la mujer de Julio Méndez, un escritor chileno exiliado en España, ansioso de ser reconocido como novelista superior. Un sentimiento de fracaso lo inunda cuando una novela suya es rechazada por Núria Monclús, su agente literario, mujer poderosa cuyas decisiones no se discuten (sin duda un doble ficticio de Carmen Balcells, agente literario y editora de escritores del "boom" latinoamericano). Julio narra en primera persona, como "autor", lo que leemos: el relato de su historia y la de Gloria. Pero en la última parte de la novela ya no es Julio quien narra en primera persona la historia, sino Gloria. Inicia su relato conversando, relajada, justamente con la mujer que había rechazado la novela de Julio, Núria Monclús. De la conversación el lector infiere que Julio no es exactamente el autor de su relato, sino el personajenarrador de un relato cuyo autor es otro: Gloria. Como Donoso, Gloria, la "autora", también lleva unos "cuadernos" personales, en otras palabras, un diario íntimo, sugiriendo así (junto a otros datos cuyo significado se mueve en 
la misma dirección) la identidad del propio Donoso. De nuevo: deslizamientos de identidades, desdoblamientos donde el autor no es más que un personaje de otro autor. ¿Será Donoso el autor de El jardín de al lado? ¿No habrá otro autor que a su vez lo ha imaginado a él, o "soñado", como diría Borges?

Un tono distinto, de mayor tensión, encontramos en un caso de desdoblamiento descrito en el Diario, donde el doble no es ya una proyección interior y libre del yo, sino el producto externo de una maquinaria policial y burocrática. En vez de una figura amable o querible, tenemos ahora un doble fantasmal, portador de signos negativos, sombríos, peligrosos, agresivos incluso, oscilaciones éstas bien conocidas por el psicoanálisis, e ilustradas en la literatura, por ejemplo, por la novela El doble de Dostoievski. Este nuevo caso se origina en el aeropuerto de Santiago y en una ocasión en que Donoso se dispone a viajar al extranjero. Entonces es detenido por la policía que busca a un estafador con el mismo nombre. Donoso anotará en su Diario: "El espectro de otra persona con mi nombre. El José Donoso estafador, que me persigue y me hace la vida imposible, con el que me identifico e inmediatamente que me identifico, me hace daño, el que tiene todo lo bueno, lo benéfico y dañino mío, que tengo separado en dos, pero que finalmente es -soy, es- uno mismo" (...). "El tema del doble, el espectro de otra persona con mi nombre. El José Donoso estafador de poca monta, que me persigue y me hace la vida imposible. Cómo me roba cosas, cómo me destruye la vida, cómo lo necesito para seguir viviendo. ¿Tiene algo que ver con Cástor y Pólux?” (Pilar Donoso 399) ${ }^{8}$.

Esta proyección del yo en su doble negativo, o mejor, esta división o fractura del yo en dos yo, el "benéfico" y el "dañino", que son las dos caras de la misma moneda, queda a la vista, bajo modos diversos, en no pocas páginas del Diario. El yo dañino se manifiesta a veces como una suerte de "contaminador" del otro yo: lo "contagia". Así surge el tema de la mancha, de sentirse "sucio", y por lo mismo de temer que los demás se alejen de él, que no lo quieran, una de las tantas obsesiones del Donoso. A propósito de una reunión social a la que asiste en 1991, escribe: "Noté exactamente el momento en que, en la visita, Joaquín Lira, el socio de Carmen Paz, cambió en su actitud, un feeling con respecto a mí: como si en mí hubiera descubierto, de repente, un montón de mierda, y le estuviera, desde ese momento en adelante, haciendo ascos terribles. Yo soy mierda. Yo soy mierda. La gente

8 Cástor y Pólux son personajes de la mitología griega, hijos mellizos de Zeus y Leda, también conocidos como "Géminis". 
me hace ascos. Joaquín Lira me hace ascos. ¿Es verdad o es pura paranoia?" (Pilar Donoso 32). En otro momento, reflexiona en torno a este sentirse sucio y confiesa que es un sentimiento que lo ha acompañado toda su vida. "Por qué siempre he tenido la sensación de ser, de estar sucio (...). Siempre me he sentido relativamente sucio, calzoncillos, camiseta, y muchas veces casi se podría decir que lo he cultivado". "... y mientras escribo, o leo cualquier cosa, tengo una infaltable sensación de suciedad, como si hiciera un mes que no me lavo" (Pilar Donoso 35). Recordemos que Otto Rank decía que el "narcisismo primitivo" regresaba, en los desdoblamientos paranoicos, bajo la forma de una "homosexualidad sublimada". No caben dudas: la mancha, el sentirse "sucio", no pueden sino ser signos de una homosexualidad sublimada, pero, en el caso de Donoso, de una homosexualidad secretamente sentida como culpa: mancha es culpa en este contexto.

Hay todavía un complejo de desdoblamientos que quisiera analizar para ir terminando este ensayo. El mendigo urbano es el centro de este complejo. Donoso habla de él nombrándolo a veces con la palabra francesa "clochard". En una de las páginas publicadas en el diario $A B C$, cuando ya llevaba casi una década en Santiago desde su regreso a Chile, nota que echa de menos "sobre todo a los mendigos". Esos mendigos cuyas "pistas" seguía, "han desaparecido de Santiago, que parece una ciudad distinta sin ellos, pese a que en la superficie no se comunican con nadie: pero tienen, cada uno, su lugar, su ritmo incluso, y sus espacios están estrictamente marcados: para mí, pienso, son lo más marcado de toda la ciudad" de Santiago (Patricia Rubio 541). Es notoria la atracción que ejerce en Donoso el mendigo. Aparece y reaparece en las anotaciones de su Diario. Pero, para el tema u objeto específico de nuestro análisis (el desdoblamiento del yo), es necesario reparar en algunas descripciones donde el mendigo deja de ser la simple figura de un escenario, alguien recordado, aun cuando el recuerdo revele una curiosidad de alguna manera comprometida.

Son descripciones que desplazan la imagen del mendigo desde afuera hacia adentro, en un proceso de interiorización que termina haciendo del mendigo, del "clochard", un doble del yo. La de este mendigo tal vez sea una de las imágenes más intensas, y esclarecedoras en muchos aspectos, del Diario. En 1961 anota que la imagen del mendigo lo perseguía, que había sostenido largas conversaciones con su psiquiatra sobre "esa figura que me acosaba, por la que sentía un atractivo feroz y un terror espantoso". Recuerda la envidia que le provocaba "ese hombre que no tenía miedo porque no tenía nada que perder, cómo el clochard quedaba situado fuera del miedo, fuera 
de la envidia, como era, de alguna manera la imagen del poder, yo quería ser él" (Pilar Donoso 46). Claramente, se ve, el mendigo es un doble de Donoso, una expresión proyectada de su yo dividido y paranoico. Representa el yo que no es pero que quisiera ser. Lo que le seduce en él es que se sitúa (o lo sitúa) en un afuera de los marcos sociales, más allá y al margen de la necesidad de tener que exhibir una identidad (social, sexual, etc.). El mendigo despierta en él un irresistible deseo de "abandonarlo todo, de borrar mis huellas, de dejar atrás mi identidad y ser uno de ellos" en cualquier lugar donde se hallara.

En última instancia, lo que Donoso ve en el mendigo, lo que objetiva en él, es un estado de libertad pura y absoluta: ser como él "un ser totalmente destituido" no solo de reglas, imposiciones, convenciones, sino también de sus "huellas", es decir, de los signos de su ser en el tiempo, en otras palabras, de su historia. Por lo tanto, un ser "totalmente destituido" es un ser sin historia. ¿Pero un ser sin historia, sin tiempo, no es ya alguien que ha dejado de ser propiamente humano? Ser ese mendigo que lo atrae, su doble, ¿no significa, al final, asumir el destino de El Mudito, el personaje de El obsceno pájaro de la noche, es decir, convertirse en un monstruo, un invunche, un no-humano que ha perdido justamente lo que hace al ser humano: el lenguaje, la palabra? Así se entiende por qué el reverso del sentimiento de seducción es precisamente el sentimiento de "un terror espantoso". El terror de no ser, de la nada, de la mudez, en otras palabras, el terror de la muerte.

El sentido de este "terror espantoso" recibe de Freud una precisión indispensable de recordar aquí. Continuando la reflexión de Rank sobre el doble como fijación en el narcisismo primario, pensaba que, siendo el doble una "formación oriunda de las épocas primordiales del alma ya superadas", su retorno en etapas posteriores de la evolución del yo devenía en una "figura terrorífica", portadora de un carácter que él llama "ominoso". Al retorno de este doble con su carácter ominoso pueden asociarse, según Freud, "todas las posibilidades incumplidas de plasmación del destino, a que la fantasía sigue aferrada" (Sigmund Freud b) 236). No es entonces casual, desde esta perspectiva, que en la anotación de su Diario en la que da cuenta de su visita al psicoanalista a propósito del clochard y de su acoso, Donoso hable de su "largo prontuario de solterón", de las huellas "profundas y dolorosas" que ha dejando en él, de que experimenta una "especie de embotellamiento" y de que vive "una vida que no me gustaba" (Pilar Donoso 383 y 384).

Era impensable que un tema como el doble, con tan profundas implicaciones biográficas, de identidad subjetiva, no tuviera un lugar importante en la imaginación narrativa de Donoso. De hecho ya se advirtió cómo el registro 
en el Diario de la escena en que Donoso observa a una joven hermosa en el jardín y menciona, al pasar, el nombre de Gloria, ponían en juego paralelo a la novela El jardín de al lado con sus desdoblamientos de identidad en el plano de la "autoría". Pero sin duda es El obsceno pájaro de la noche la novela donde el doble y lo ominoso ocupan un lugar central, sin excluir los paralelismos biográficos. El mismo Donoso anota en su Diario cómo el caso de Jorge Sanhueza (una figura conocida dentro del mundo de los escritores y artistas chilenos de las décadas del 50 y del 60) y sus relaciones con el matrimonio formado por el pintor Nemesio Antúnez e Inés Figueroa, constituiría el modelo a partir del cual habría imaginado su doble novelesco, formado por el matrimonio Jerónimo e Inés y sus relaciones con Humberto Peñaloza, el Mudito. A su vez, dentro de la novela, las parejas Humberto Peñaloza-Peta Ponce y Jerónimo de Azcointía-Inés representan dos polos, el luminoso y el oscuro, el ejemplar y el deforme, pero son polos entre los cuales existe una relación de implicación recíproca, donde uno es el doble invertido del otro, la contracara del otro, a la manera en que también lo eran Donoso y su clochard. En El obsceno pájaro de la noche se describe claramente esta relación a propósito del hijo de Jerónimo e Inés que iba a nacer: "Jerónimo había logrado por fin sacar a Inés al medallón estático de la dicha conyugal perfecta: ayudada por su mano galante la conduce para tomar las actitudes prescritas en el siguiente medallón, en que figurarían como padres. Mientras la Peta y yo, seres fantásticos, monstruosos, grotescos, cumpliríamos con nuestra misión de sostener simétricamente desde el exterior ese medallón, como un par de suntuosos animales heráldicos" (José Donoso 228). Son por lo demás las clásicas relaciones de implicación recíproca entre patrón y sirviente, tan importantes en Donoso.

Si el doble, en el estudio de Rank, es una figura de origen paranoico y, en tanto tal, expresión de una homosexualidad sublimada, el sentido de su condición, visto desde El obsceno pájaro de la noche, no se agota en los personajes y en las sorprendentes relaciones que mantienen entre sí. Hay algo más. Este algo más afecta a la novela como mundo y como orden narrativo. De toda la producción novelesca de Donoso, esta novela, la más intensa, ofrece un mundo donde el sujeto fracturado, dividido y desdoblado, incluso sexualmente (el mismo sujeto es él y ella, como el Mudito en la Casa de Ejercicios) es llevado a su expresión más absoluta, más sistemática y más perturbadora. Pero como no podía ser de otra manera: mundo y orden narrativo se corresponden en su sumisión a la misma lógica. En efecto, el orden narrativo (el discurso narrativo) parece estar presidido por un principio 
paralelo de ruptura permanente de las coordenadas espacio-temporales, hasta el punto de que el lector se ve compelido a cruzar planos diversos de acción, a descubrir puentes de sentido entre estos planos, a participar en un juego donde el comienzo y el fin intercambian lugares, y, por último, se ve precipitado hacia el punto de llegada de un discurso donde el mismo, como discurso, parece hacer suya la disolución del personaje en la nada, en el silencio, en la muerte: la muerte, decía Donoso, es la falta de lenguaje. Tal vez no sea un despropósito afirmar que esta novela está construida a partir de un modelo paranoico. Con lo cual no estoy practicando un reduccionismo. Estoy sí postulando, en El obsceno pájaro de la noche, una construcción verbal, estética, literaria que da cuenta de sí misma, de su autonomía, de su propia libertad imaginativa, pero una construcción cuya disposición y lógica remiten al modelo paranoico.

\section{BIBLIOGRAFÍA}

Donoso, Pilar. Correr el tupido velo. Santiago: Alfaguara, 2009.

Donoso, José. El obsceno pájaro de la noche. $2^{\mathrm{a}}$ ed. en Chile. Santiago: Editorial Planeta, 1992.

Fontaine Talavera, Arturo. "Documentos íntimos de José Donoso". Publicado en El Mercurio el 17 de diciembre de 3003.

Freud, Sigmund. El malestar en la cultura. Madrid: Alianza Editorial, 1990.

"Lo ominoso". Obras completas. Vol. XVII. Buenos Aires: Amorrortu Editores, 2009.

Matus, Álvaro. "El infierno sin límites de José Donoso". Entrevista a Pilar Donoso. Publicada en el diario La Tercera, sección Cultura, el 5 de diciembre de 2009.

Morales T., Leonidas. “Alone: Diario de un lector”. Anales de Literatura Chilena $\mathrm{N}^{\mathrm{o}} 20$, diciembre de 2013.

Ortega, Julio. "Los papeles de José Donoso". Publicado en el suplemeno Cultura y Nación del diario argentino Clarín el 21 de agosto de 2003.

Soto, Marcelo. Publicó, en el 2003, en la sección Reportajes del diario La Tercera los siguientes artículos: "Los cuadernos íntimos de José Donoso" (27 de abril), "Los amores de José Donoso" (4 de mayo) y "Los años difíciles de José Donoso (11 de mayo).

Rank, Otto. El doble. Traducción de Floreal Mazía. Buenos Aires: Ediciones Orión, 1976.

Rousset, Jean. “Le journal intime, texte sans destinataire?”. Poétique. Paris, № 56, noviembre de 1983.

Rubio, Patricia, comp. José Donoso. Diarios, ensayos, crónicas. Santiago: RIL Editores, 2009. 